Artículo Científico Original

\title{
TRABALHADORES \\ DENUNCIAM O TRABALHO ESCRAVO
}

Ricardo Rezende Figueira

Adonia Antunes Prado 
TRABALHADORES

DENUNCIAM O TRABALHO

ESCRAVO*

\section{Ricardo Rezende Figueira}

Doutor em Ciências Humanas (com ênfase em antropologia). Professor da Universidade Federal do Rio de Janeiro (UFRJ); Coordena o Grupo de Pesquisa Trabalho Escravo Contemporâneo do Núcleo de Estudos de Políticas Públicas em Direitos Humanos (GPTEC/NEPP-DH) da mesma universidade.

Adonia Antunes Prado

Doutora em Educação Brasileira. Professora da Faculdade de Educação da UFRJ e do Programa de Pós-Graduação em Educação da Universidade Federal Fluminense e pesquisadora do GPTEC/NEPP-DH/UFRJ.

\section{RESUMO}

O artigo apresenta um estudo realizado a partir de depoimentos, prestados no decorrer de quatro anos por pessoas que escaparam ou foram libertados de unidades rurais de produção, no sul do Pará. Em todos os casos, há indícios de que os depoentes sofreram o crime de prática de trabalho análogo à escravidão. Buscouse neste texto identificar quem fala, como fala, para quem e quando fala e a reação de autoridades ao problema.

Palavras-chave: trabalho escravo contemporâneo; trabalho, violência e medo no campo brasileiro; Amazônia brasileira.

\section{LABORERS REPORT SLAVE $L A B O R$}




\section{INTRODUÇÃO}

Os autores estudaram 340 depoimentos de trabalhadores rurais, recolhidos por diversos agentes sociais nos estados do Pará, Tocantins e Maranhão, entre 2004 e 2007. Os depoimentos foram prestados por pessoas que estiveram em algum momento em situação de escravidão contemporânea, ou em situação considerada análoga à de escravo, conforme o art. 149 do Código Penal Brasileiro (CPB), em propriedades do sul do Pará. Aqui o leitor verá o desdobramento de dados que revelam quem prestou 0 depoimento, como, para quem e com que objetivo falou, quando as informações foram recolhidas e o papel das autoridades. O estudo faz parte de uma pesqui$\mathrm{sa}^{1}$ maior ainda inédita, que envolveu um grupo numeroso de colaboradores no GPTEC e a assessoria de frei Xavier Plassat e Ana de Souza Pinto, agentes da Comissão Pastoral da Terra (CPT), com depoimentos que abrangem um período de mais de 30 anos, a respeito do mesmo problema na mesma região.

\section{Os denunciantes e suas expectativas}

Homens, mulheres e menores, ao saírem em fuga de unidades de produção no Pará, retornam para casa, que em geral fica em outro município ou estado, ou não - fazem por não terem para onde ir. Uns e outros buscam novo trabalho. Os primeiros, onde moram ou em outras regiões - estes cultivam as relações de parentesco, por isso o retorno, mesmo se temporário, ao local de moradia. Os segundos, onde estão ou em outras áreas - estes são conhecidos como peões do trecho, com relações de parentesco rompidas. A escassez de recursos, a falta de vínculos definitivos, os torna permanentemente nô-

Apoiada pelo Conselho Nacional do Desenvolvimento Científico e Tecnológico mades, mantendo um ciclo no qual consta uma alternância aparentemente sem saída entre fazenda, pensão, fazenda.

Entre os fugitivos, alguns procuram alguém ou uma instituição pública ou privada onde relatam o que sofreram e sua história é registrada e pode ter ou não algum desdobramento. Outros, porque não têm uma consciência clara do próprio direito, ou de que encontrariam acolhimento na denúncia, e/ ou não sabem para quem denunciar, mantêm-se em silêncio. $O$ estudo se refere ao primeiro grupo, esse que formulou uma reclamação e esta foi transformada em texto e arquivada em meio digital ou físico. O recorte é composto por casos ocorridos no Pará e a maioria das denúncias partiu de trabalhadores em atividades agropecuárias e, em seguida, denúncias de trabalhadores em produção de carvão vegetal.

Quem denuncia o faz movido por um sentimento de indignação por direitos que teriam sido lesados, porque se considera humilhado pelo empregador ou de seus prepostos. Trata-se de uma gente em busca da reposição de um estado de justiça que teria sofrido uma ruptura inadmissível.

Os depoimentos dos casos estudados revelam de alguma forma a expectativa dos denunciantes quanto à resposta do Estado, e como o Estado, através de seus órgãos, acolheu a reclamação. $O$ fato em si de procurar a "justiça" significa acreditar que pode haver uma resposta. Aquele que denunciou o fez, em última instância, porque acreditou que algo podia e seria feito; que sua reclamação seria ouvida; que haveria uma reposição de seu direito. Que os interlocutores compreenderiam suas reivindicações e teriam os instrumentos adequados para auxiliá-lo e para punir quem o havia prejudicado. Contudo, porque varia o momento da denúncia? Porque alguns demoram mais de 
ano para fazê-lo? Nesse sentido, poderíamos pensar em dois grupos compostos pelos "depoentes" ou "denunciantes". Um é aquele que sentiu mais rapidamente que seus direitos foram violados e denunciou; o outro, aquele que demorou meses e mesmo anos para fazê-lo.

As razões para se ter rapidez ou demora são o resultado do nível de consciência do que é justo ou legítimo por parte da pessoa atingida, e ele não é uniforme; do grau de exploração ou violência que difere entre os proprietários e seus representantes; da possibilidade objetiva ou subjetiva de deslocamento e acesso a interlocutores confiáveis ${ }^{2}$. E o deslocamento pode significar graus diferenciados de facilidades ou dificuldades: à distância, a rede de relações estabelecidas, o conhecimento da região, das instituições existentes. Em alguns lugares o acesso só foi possível de barco; outros, de barco e a pé. Havia locais com estradas, mesmo que precárias, mas onde não passavam carros de forma regular pela existência de correntes ou porteiras, definindo os limites da propriedade e do acesso; ou passavam carros, mas os trabalhadores não tinham dinheiro para pagar a passagem e dependeriam de um transporte gracioso.

Quem decidiu fazer a denúncia considerou que houve uma violação de seu direito ou uma ofensa sofrida e, em um e outro caso, a situação era inadmissível, havia ultrapassado o aceitável e o interlocutor, era confiável; apesar dos riscos de uma reação mesmo violenta do denunciado, valia a pena reclamar ${ }^{3}$.

Sobre o trabalhador, considerado pelo estado brasileiro como vítima do trabalho análogo ao escravo, há estudos e pesquisas concluídos e em curso. Alguns, re-

2 Para uma discussão sobre as bases sociais da indignação, ver Moore Jr. (1987). 3 Os depoimentos não revelam as ações posteriores: as fiscalizações, as punições e as reparações aos erros. centes, são frutos de pesquisa de campo (OIT, 2007 e Costa, 2010); outros, com ou sem pesquisa de campo, foram publicados especialmente ao longo das décadas de 1970 aos anos 2000. Há os publicados regularmente por organizações como a Comissão Pastoral da Terra e a Rede Social de Justiça e Direitos Humanos ${ }^{4}$ e outros por estudiosos ligados de alguma forma a universidades do país e do exterior $^{5} \mathrm{~A}$ literatura sobre o tema aumentou a partir de 1995, como aumentou a sensibilidade sobre o problema em um público mais vasto e cresceram as ações do estado contra o crime, mesmo se o problema persiste na cidade e no campo; em regiões distantes do Norte brasileiro e em áreas metropolitanas do Sudeste (Figueira e Prado, 2009: 78-82) ${ }^{6}$.

\section{Quem acolheu a informação}

Em geral, a denúncia é acolhida por um agente social que pertence a uma instituição de cunho religioso, de organização de classe ou governamental. Quanto ao primeiro caso, há a Comissão Pastoral da Terra (CPT). A organização, através de seus membros, voluntários ou assalariados recebe os trabalhadores em seus escritórios distribuídos em sete cidades paraenses - Altamira, Belém, Marabá, São Félix do Xingu, Tucumã, Tucuruí e Xinguara -, e fora do Estado, em Araguaína, no Tocantins, e em Balsas, no Maranhão.

Há uma média de 85 depoimentos recolhidos e ou arquivados por ano pela CPT no período selecionado para o estudo: em 2004, 70; em 2005, 85; em 2006, 97 e, em 2007, 88 (cf. Quadro 1). Destes,

\footnotetext{
A CPT, desde 1986 publica anualmente Caderno Conflitos no Campo, com um balanço da violência expressa, entre outros aspectos, nas questões pelo uso e posse da terra e no trabalho escravo. A Rede Social de Justiça e Direitos Humanos, no seu relatório anual, tem aberto espaço para pequenos textos sobre o tema.

5 Veja, em uma leitura extensa, entre outros, Almeida (1988); Bouclet (2005); Cavalcanti et al. (2008); Esterci (1994); Martins (1994); Moura (2009); Santos (2002); Castillo (2008); Figueira (2004); Bales (2000); Zanin (2007), dentre outros. 6 Figueira (2009); Le Breton (2002) e Prado (2010), dentre outros, além do I e II Plano Nacional pela Erradicação do Trabalho Escravo, respectivamente, 2003 e 2008.
} 
$36(10,58 \%)$ são provenientes de outra fonte que a CPT, como o sindicato de trabalhadores rurais (STR), organizações de Direitos Humanos e do Ministério do Trabalho e Emprego (MTE). O Centro de Defesa da Vida e dos Direitos Humanos (CDVDH) de Açailândia, por exemplo, sozinho recolheu 18 dos depoimentos.

Se a maioria, quase $90 \%$ dos depoimentos, são dos nove escritórios da CPT, chama atenção o escritório da CPT de Marabá que sozinho recolheu 190 (62,5\%) depoimentos dos 304 recolhidos pela pastoral da terra.

Em alguns casos, os depoentes estiveram antes ou depois em alguma repartição governamental, no STR ou em uma organização dos Direitos Humanos. Denunciaram ali porque sabiam de algo sobre a prática da organização; foram informados ou indicados por alguém; orientados por outro trabalhador ou porque ouviram falar pela imprensa da ação do Estado; já haviam sido anteriormente libertados pelo Grupo Móvel ${ }^{7}$ e adquiriram experiência sobre o papel dos fiscais do trabalho e da PF. Destas organizações, foram encaminhados a um escritório da CPT. Por exemplo, um trabalhador esteve no STR de Redenção, antes de ir a CPT/Xinguara; no STR de São Félix do Xingu, antes de ir a CPT/Tucumã; no Balcão dos Direitos e no Centro de Defesa da Vida e dos Direitos Humanos (CDVDH) de Açailândia, no Centro de Direitos Humanos de Ananás, na PF de Marabá, em Subdelegacias de Trabalho de Marabá e Araguaína, antes de ir a CPT/Marabá e Araguaína.

Na maioria das vezes, os depoentes foram diretamente aos escritórios da CPT, orientados por quem era mais próximo, como um companheiro, outro trabalhador

7 Um trabalhador, que solicitou ficar no anonimato, havia sido liberto três vezes antes pelo Grupo Móvel (documento de 11.11.05. referente à Carvoaria Bamerindus, Novo Paraíso).
- idoso e doente ${ }^{8}$-, um "moto taxi" ou um padre da igreja local e este fato se explica pelo tempo de inserção da CPT em questões relativas ao tema. Mas, se a CPT continuou sendo aparentemente a organização mais procurada, outras organizações começaram a ser parceiras. O Núcleo dos Direitos Humanos de Araguaína, no Tocantins, recebeu um trabalhador em 2005 e, cinco, no ano seguinte; o Núcleo dos Direitos Humanos de Araguanã, TO, recebeu denúncia em 2005, redigiv e encaminhou para a CPT/Araguaína e ao Ministério Público do Trabalho.

Raramente o agente da CPT, ao colher a denúncia, registrou $\circ$ desdobramento da ida do trabalhador às autoridades. Provavelmente não o fez naquele instante porque os funcionários públicos não tiveram tempo de encaminhar uma ação; ou porque o próprio trabalhador não soube informar. Contudo, mesmo se raras, pode haver alguma medida sendo tomada. Por exemplo, um dos depoimentos informou que os funcionários da subdelegacia de polícia de Tucuruí, PA, ao receberem a denúncia, intimaram o empreiteiro, conhecido como gato, através do próprio trabalhador. Houve casos, dadas as suas especificidades, nos quais os funcionários do MTE da região encaminharam os trabalhadores para a PF. Em Marabá, funcionários do MTE receberam um informante e, como havia ameaça de morte, 0 encaminharam à PF. $O$ agente que 0 recebeu, contudo, disse que não podia resolver o problema e o reencaminhou para a CPT da cidade.

Tais fatos revelaram que algumas autoridades foram procuradas e caberia uma pergunta: entre elas, qual foi o interlocutor considerado confiável para o trabalhador que buscou uma solução para o seu caso e, muitas vezes, a solução para

8 Documento de 22.08.05. Referente a Faz. do Elcio, São Félix do Xingu. 
o grupo? $\bigcirc$ interlocutor foi procurado, às vezes em município diferente do local do crime, no mesmo estado ou em estado diferente e os trabalhadores encontravam mais razões para confiar em autoridades federais que estaduais. A autoridade, quanto mais distante, parecia melhor, menos envolvida com os interesses locais. E a prática de recorrer ao Exército era antiga e até final de 1984, antes do retorno do governo civil, quem "dava as cartas" nas tensões e conflitos no Araguaia paraense era a $8^{a}$. Região Militar, instalada em Marabá. Assim os problemas não eram levados ao juiz, ao promotor local ou ao delegado da comarca. No período do governo militar, a autoridade governamental mais procurada era aquela conhecida como "federal", que era identificada como o Exército, através da $8^{a}$ Região Militar ou pela PF.

\section{A autoridade}

Às vezes a ação da autoridade pareceu ambígua ou simplesmente condenável. É possível constatar o fato por alguns exemplos envolvendo policiais civis e militares paraenses. A pessoa corria risco de ser devolvida para o imóvel de onde escapou. E o problema persistiu mesmo após a ditadura. Por exemplo, em 1990, alguns que escaparam da Agropecuária São Luís, no município da Floresta, só não foram devolvidos à fazenda pela intervenção de uma agente pastoral'? Em fevereiro de 2006, em Nova Lacerda, Mato Grosso, no transcurso de operação de fiscalização coordenada pelo Grupo Móvel, a PF, que a acompanhava, foi atacada a balas por policial militar que dava respaldo ao fazendeiro ${ }^{10}$.

9 A missionária francesa e leiga Paulette Planchon, com 73 anos, morava em Floresta, que pertencia ao município de Conceição do Araguaia, Pará, e se tornaria sede de um novo município no Estado.

10 Veja Recurso Criminal 2006.36.01.000810-5/MT que tramita no Tribunal Regional Federal da Primeira Região: http://www.elciopinheirodecastro.com.br/ documentos/primeira/abril10/16_04_2010.pdf. Acesso em 28.06.2010.
A delegacia de polícia de São Geraldo teria recebido denúncia de ameaça de morte, mas não marcou a audiência, reclamou o trabalhador ${ }^{11}$. Ameaçado de morte pelo fazendeiro, saiu deixando tudo que possuía, registrou ocorrência na delegacia de polícia de Ourilândia, mas nada foi feito ${ }^{12}$. Havia suspeição sobre a PM de Uruará que passaria informação para um fazendeiro sobre deslocamentos do Exército para a região ${ }^{13}$. Um cabo da PM seria um dos gatos de uma fazenda ${ }^{14}$; um sargento trabalharia para um fazendeiro e receberia bezerros de presente ${ }^{15}$; a PM era amiga do gerente de determinado fazendeiro, recebia presentes e podia ser acionada contra os trabalhadores $^{16}$. O funcionário da fazenda, chefe das máquinas, "humilhava" os tratoristas gritando. Quando um destes quis "acertar" para ir embora, gritou e lançou-lhe uma cadeira, provocando lesões. Não satisfeito, foi a Gogó da Onça e retornou com três PM fardados que retiraram o trabalhador da fazenda, mas, aí pareciam generosos, pediram ao funcionário da empresa contratante que pagasse a passagem do homem para Xinguara ${ }^{17}$. A serraria envolvida com trabalho escravo daria propina para a PM e para o fiscal da Secretaria de Estado da Fazenda (SEFA) ${ }^{18}$.

Há casos que envolvem autoridades locais e federais. A polícia civil de Tucumã, que auxiliou os trabalhadores contra um fazendeiro e seu gato e os encaminhou para a PF de Redenção, teria pedido dinheiro a estes. A PF os recebeu e os encaminhou ao $M T E$, que os enviou para a Justiça do Trabalho, que os encaminhou para o STR,

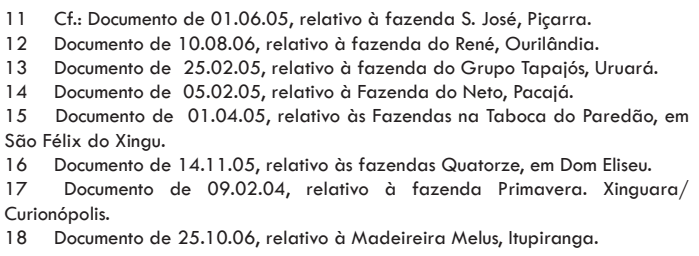


que os encaminhou para um advogado, que os encaminhou para a CPT/Tucumã para que retornasse à Delegacia e fizesse exame de corpo e delito ${ }^{19}$.

Depois de dois anos sem receber salários, o trabalhador caminhou quatro dias até Vila Mandi e conseguiu uma carona. Em Redenção teria procurado a subdelegacia do trabalho que nada podia fazer, pois o trabalhador não tinha CPF; foi à $\mathrm{PF}$ que mandou voltar à DRT, decidiu ir à $8^{a}$ Região Militar em Marabá. Não tinha dinheiro para ir tão longe e foi a Xinguara, onde $\circ$ irmão do presidente do STR the indicou a $\mathrm{CPT}^{20}$. Presenciou o gerente da fazenda enforcar um trabalhador e soube de outras três mortes, por isso foi à cidade, procurou a PF para formular a denúncia, mas não havia delegado na cidade $^{21}$. Procurou a PF em Belém, prestou depoimento mas nada assinou nem recebeu qualquer documento ${ }^{22}$.

O poder público, expresso no Judiciário, na Defensoria Pública e na Promotoria do estado, está sintomaticamente ausente na história de defesa e libertação destes homens e mulheres. Ou, se manifesta, pode fazê-lo de uma forma considerada inadequada pelo denunciante. Há dois depoimentos, um de 2004 outro de 2005, que citam duas promotoras que demonstram o desconforto que trazem para as chamadas vítimas. Sobre a primeira, aquela de 2004, ela teria recebido em audiência os fugitivos de uma fazenda do município de Ourilândia. Preparou uma notificação que os próprios trabalhadores denunciantes deveriam entregar ao proprietário. Amedrontados pela terrível tarefa, os três homens e a mulher procuraram a CPT/Tucuma $\tilde{a}^{23}$. A segunda promotora, en-

9 Documento de 04.08 .05 , relativo Fazenda do Antônio, São Félix do Xingu 0 Documento 44, de 24.05.06, relativo à fazenda Terra Roxa, Santana do Araguaia?

21 Documento de 12.06.06, relativo à fazenda Entre Rios, Medicilândia.

22 Documento de 23.11 .06 , relativo à fazenda Manga Larga, Paragominas.

23 Documento de 13.08.04, relativo à fazenda Araguaxim II, Ourilândia do Norte quanto recebia uma denúncia, conversou por telefone com o fazendeiro acusado e mudou de comportamento. O homem, surpreso, decidiu procurar a $\mathrm{CPT}^{24}$.

Se a omissão das autoridades torna mais grave a história dessa gente, ela pode ainda ser pior, se a autoridade for proprietária de imóvel denunciado. A administração da fazenda de um deputado estadual não era correta no pagamento dos funcionários, a comida e as condições sanitárias eram inadequadas, não cumpria com obrigações trabalhistas e dificultava a saída dos trabalhadores ${ }^{25}$. Um segundo seria desembargador e, em sua fazenda, o alojamento e as condições sanitárias eram inadequadas, mantinha empreiteiro que portava arma e ameaçava os trabalhadores ${ }^{26}$. E havia os prefeitos. O prefeito de São Pedro de Água Branca, Maranhão ${ }^{27}$; e aquele de Abel Figueiredo, no Pará ${ }^{28}$. Outro era ex-prefeito de Pacajá, Pará, que tinha como confrontantes dois irmãos e os trabalhadores eram remanejados entre as fazendas ${ }^{29}$. Finalmente, poderíamos ainda citar o de Japi, Rio Grande do Norte, que aliciava inclusive menor, transportava de forma irregular pessoas, burlava a fiscalização da polícia rodoviária; não pagava adequadamente e seria denunciado por dois que fugiram da fazenda às duas da madrugada, apenas com a roupa do corpo $^{30}$.

A autoridade podia também representar esperança e segurança para o trabalhador $e$ insegurança para aquele que cometia o crime. Não foi sem razão que um fazendeiro, no transporte de trabalhadores, se preocupou quando se

24 Documento de 25.02.05, relativo à fazenda do Grupo Tapajós, Uruará.

25 Documento de 16.11.2004, relativo à fazenda Uberaba, Bom Jesus do Tocantins.

26 Documento de 27.05.04, relativo à fazenda Gadote, Piçarra.

27 Documento de 13.10.06, relativo à fazenda do Juca, Abel Figueredo.

28 Documento de 16.10.06, relativo à fazenda Jesus de Nazaré, Abel de Figueredo.

29 Documento de 14.08.06, relativo à fazenda Lago Azul, Pacaiá.

30 Documento de 27.05.04, relativo à fazenda Índia Sul, Palestina. 
aproximou da polícia rodoviária e buscou formas de burlar a vigilância ${ }^{31}$. A PF gozou de prestígio junto aos trabalhadores, quanto ao seu poder de solucionar os problemas, como demonstraram diversos depoimentos. Em um deles, a mulher e o marido eram ameaçados e perseguidos. $\mathrm{Na}$ fuga, o marido desapareceu. $\mathrm{O}$ único caminho que ela vislumbrou foi ir a $\mathrm{PF}^{32}$. Outro depoimento, de junho de 2006, revelou a situação difícil por que passavam os trabalhadores. A comida estava deteriorada, havia humilhações, o pagamento não era efetuado, a dívida persistia e um dos trabalhadores resolveu denunciar. Um companheiro, o Fraqueza, que havia sido resgatado pelo Grupo Móvel em outra oportunidade, os orientou a procurar a Polícia Federal em Marabá, pois ali eles teriam lugar para se hospedar enquanto aguardavam a fiscalização ${ }^{33}$. Neste caso, o trabalhador atribuía à $P F$, não a solução do problema, mas a intermediação. Ao ser liberto, o denunciante, provavelmente percebeu que, na operação, o protagonismo era da equipe do MTE, mas a PF estava junto e protegia a equipe e os trabalhadores. Em alguns depoimentos, se constatou que os agentes da PF receberam trabalhadores e os encaminharam a algum escritório da $\mathrm{CPT}^{34}$; ou agentes da PF em Redenção receberam um trabalhador vindo de uma fazenda de Santana do Araguaia e o encaminharam para a CPT de Xinguara, e lhe passaram os endereços do STR e da DRT ${ }^{35}$; outro trabalhador procurou a PF em Marabá e esta o encaminhou para a CPT/Marabá ${ }^{36}$. Um fugiu e, após 8 dias a pé, chegou a Jacundá com malária. A Polícia Civil o encaminhou

\footnotetext{
31 Documento de 23.11.06, relativo à fazenda do José de Sousa, Pacajá 22.1 1.06. Coitadinha, Pacajá.

32 Documento de 07.08 .06 , relativo à fazenda do Chiquinho, Novo Repartimento.

33 Documento de 21.06.06, relativo à fazenda Aline - também carvoaria, Breu Branco.

34 Documento de 11.01.05, relativo à fazenda do José Biancadi, município N.I; 23.06.06. do Kiko, ltupiranga.

35 Documento de 04.02.05, relativo à fazenda Maná. Santana do Araguaia. 36 Documento de 06.12.05, relativo à fazenda Santa Helena, Canaã dos Carajás.
}

ao hospital e o delegado depois o levou à PF de Marabá. Ali a PF o encaminhou à $\mathrm{CPT}^{37}$.

Se a PF era muito procurada - houve pelo menos quatro outras histórias que revelaram que a $\mathrm{PF}$, sendo procurada por trabalhadores entre 2004 e 2006, os orientou a procurarem um dos escritórios da $\mathrm{CPT}^{38}$-, o Exército também emergiu em depoimentos de 2004 a 2006, relativos aos casos de Uruará, São Félix do Xingu e Anapu, como locais de registro de denúncia ${ }^{39}$. Membros do Exército, por exemplo, coletaram depoimento relativo a um dos casos e os soldados procuraram em vão durante dois dias a fazenda denunciada. Encaminharam então o informante para a polícia civil; a polícia civil - encaminhou para a polícia militar; a militar para a $\mathrm{PF}^{40}$. Os tempos mudaram e - exército não resolvia o problema por própria conta, como nas décadas anteriores. Um soldado do exército orientou um trabalhador a procurar a CPT/São Félix do Xingu ${ }^{41}$. Em Pacajá, João fugiu e encontrou gente do exército e funcionários do INCRA que o acolheram e conseguiram que um ônibus o levasse a Marabá. Em 2002, ele havia sido resgatado pelo Grupo Móvel em Cumaru do Norte ${ }^{42}$.

Não só estas autoridades foram procuradas. Menos frequentemente, houve também tentativas de solução através de outros caminhos. Uma mulher, Maria, segundo seu depoimento no Conselho Tutelar da Criança ${ }^{43}$, conseguiu escapar de uma fazenda. $\bigcirc$ marido, ela revelou, havia sido

\footnotetext{
Documento de 14.08.06, relativo à fazenda do Grupo Passuíta, Pacajá. Documento de 20.02.04, relativo à fazenda Minas Gerais. Marabá; 6.04.04, relativo à fazenda Água Azul ou Lagoa Azul, Tailândia; 13.10.06, relativo à fazenda Paraíso, Parauapebas; 23.11.06, relativo à fazenda do José de Sousa, Pacajá; 22.11.06, relativo à fazenda Coitadinha, Pacajá.

39 Veja depoimentos de 25.02.05. Grupo Tapajós, Uruará; 22.04.05. Tabapuã, São Félix do Xingu; 13.05.05, relativo à fazenda de Sr. Juvenal, São Félix do Xingu; documento de 14.11.06, relativo à fazenda. Alvorada, Anapu.

40 Documento 33 de. 22.04.05, relativo à fazenda Tabapuã, São Félix do Xingu.

41 Documento de 13.05.05, relativo à fazenda de Sr. Juvenal, São Félix do Xingu.

42 Documento de 82. 14.11.06, relativo à fazenda Alvorada, Anapu.

43 Criado pela Lei número 8.069, de 13.07.1990.
} 
contratado como vaqueiro e levou-a consigo e os quatro filhos. Foram instalados em um barraco precário e havia muita pulga. Sentiram-se enganados e abandonados, passavam fome e as crianças choravam. Um capanga vigiava e eram proibidos sair da fazenda. Os componentes do Conselho a encaminharam a CPT de Tucuma ${ }^{44}$.

Como é possível perceber, algumas autoridades, especialmente as federais encaminharam com frequência os trabalhadores para a CPT mais próxima, o que demonstrou, quanto ao problema da escravidão por dívida, o grau de prestígio que a Pastoral gozava junto a elas ou os limites das próprias autoridades.

O MTE nem sempre foi uma referência animadora para os trabalhadores. Nas poucas fiscalizações realizadas até meados dos anos 1990, os auditores fiscais do trabalho, subordinados às respectivas Delegacias Regionais do Trabalho, muitas vezes naturalizavam o crime e não puniam os responsáveis. Contudo, a partir da criação do Grupo Especial de Fiscalização Móvel do MTE, subordinados diretamente a Brasília, a situação mudou. O Grupo Móvel implementou operações e levou os empregadores ao pagamento dos direitos trabalhistas. $E$, especialmente a partir de 2003, com novas ofensivas do Estado e com o I e II Plano Nacional pela Erradicação do Trabalho Escravo, a ação do Grupo se tornou mais eficiente: incluiu os resgatados na lista do salário desemprego e, com o apoio do Ministério Público do Trabalho, firma Termos de Ajuste de Conduta (TAC); inclui em um Cadastro do MTE as empresas consideradas flagradas no crime do trabalho escravo. Além disso, os procuradores do trabalho passaram a mover ações por danos morais coletivos e por danos morais individuais contra os autores dos crimes.

44 Documento de 09.09.05, relativo à fazenda Santo Expedito, São Félix do Xingu
Como a imprensa passou a noticiar com certa regularidade as operações de libertação, as informações sobre tais ações passaram a ser conhecidas por muitos trabalhadores. Em função de tudo isso, os escritórios locais do MTE, na época subdelegacias regionais, foram mais procurados e os funcionários das subdelegacias do trabalho começaram a ser acionados $^{45}$.

\section{Quando foi recolhida a informação}

Nos três primeiros anos, o primeiro semestre revelou-se o período de maior recolhimento de depoimentos - 159, o que perfez $63,6 \%$ da totalidade; contudo, em 2007, o número de depoimentos recolhidos no segundo semestre superou levemente o primeiro. Ficando assim distribuídos: no primeiro semestre 43 (49\%); no segundo 45 (51\%). Nos quatro anos, temos uma média favorável ainda ao primeiro semestre, que é de 59,41\% (cf. Quadros 1 e 2).

Vejamos os meses com maior número de depoimentos recolhidos. Em 2004, foram fevereiro (época de chuva) com dez, e março com 13; em 2005, os meses maio e agosto (seca), respectivamente com 11; em 2006, março (chuva) com 17 e maio (seca) com 16; em 2007, abril com 12 e julho, com 14. Os recolhimentos se dividem entre tempo de seca e o tempo mais chuvoso. Quanto aos meses com menor recolhimento de depoimentos temos, em 2004 (assinalados em itálico no Quadro 3), foram outubro e dezembro, com um depoimento cada; em 2005, julho, com três, e dezembro, com dois; em 2006, janeiro,

45 Subdelegacias no Pará acolheram trabalhadores que fugiram ou saíram de fazendas no estado, ouviram e encaminharam à CPT: Documento de 05.03.04, relativo à fazenda Bagaço Grosso, Ipixiuna; Documento de 02.03 .04 , relativo à fazenda. Água Fria, Sapucaia; 02.03.04, relativo à fazenda. Canaã, São Félix; 16.03.04, relativo à fazenda de nome desconhecido, Santa Fé; 04.06.04. , relativo à fazenda Sem Nome, Jacundá; Documento de 11.09.06, relativo à fazenda Água Azul, ltupiranga. Subdelegacia em Araguaína, TO, recebeu trabalhador do Pará e encaminhou à CPT: Documento de 27.10.04, relativo à fazenda. Santa Luzia/ Fortaleza São Geraldo; Documento de 18.01 .05 , relativo à fazenda de Paulo Barbosa, Campos Lindos. 
Quadro 1. Depoimentos relativos aos anos 2004 a 2007, segundo semestre e ano.

\begin{tabular}{|l|c|c|c|c|c|}
\hline Ano/semestre & $\mathbf{2 0 0 4}$ & $\mathbf{2 0 0 5}$ & $\mathbf{2 0 0 6}$ & $\mathbf{2 0 0 7}$ & Total \\
\hline $1^{\circ}$ semestre & 47 & 54 & 58 & 43 & 202 \\
\hline $2^{\circ}$ semestre & 23 & 31 & 39 & 45 & 138 \\
\hline Total & 70 & 85 & 97 & 85 & 340 \\
\hline
\end{tabular}

Fonte: Arquivos da CPT com levantamento realizado no GPTEC.

Quadro 2. Depoimentos de 2004 a 2007, com a relação absoluta dos depoimentos por ano e a porcentagem dos depoimentos colhidos no primeiro semestre no mesmo período.

\begin{tabular}{|c|c|c|}
\hline Ano do depoimento & Número de depoimentos & $\begin{array}{c}\text { \% dos depoimentos } \\
\text { colhidos no 1 } \text { semestre }^{\circ}\end{array}$ \\
\hline 2004 & 70 & 60,30 \\
\hline 2005 & 85 & 61,45 \\
\hline 2006 & 97 & 61,45 \\
\hline 2007 & 88 & 48,86 \\
\hline Total & 340 & \\
\hline
\end{tabular}

Fonte: Arquivos da CPT com levantamento realizado no GPTEC

Quadro 3. Número de depoimentos colhidos segundo os meses, de 2004 a 2007.

\begin{tabular}{|l|c|c|c|c|c|}
\hline Ano/meses & $\mathbf{2 0 0 4}$ & $\mathbf{2 0 0 5}$ & $\mathbf{2 0 0 6}$ & $\mathbf{2 0 0 7}$ & Total \\
\hline Janeiro & 6 & 10 & 3 & 4 & 23 \\
\hline Fevereiro & $\mathbf{1 0}$ & 7 & 4 & 13 & 34 \\
\hline Março & 13 & 9 & 17 & 6 & 45 \\
\hline Abril & 4 & 7 & 10 & 12 & 33 \\
\hline Maio & 7 & 11 & 16 & 4 & 38 \\
\hline Junho & 7 & 10 & 8 & 4 & 29 \\
\hline Julho & 4 & 3 & 5 & 14 & 26 \\
\hline Agosto & 5 & 11 & 6 & 7 & 29 \\
\hline Setembro & 4 & 4 & 8 & 7 & 23 \\
\hline Outubro & 1 & 5 & 5 & 5 & 16 \\
\hline Novembro & 8 & 6 & 11 & 10 & 35 \\
\hline Dezembro & 1 & 2 & 4 & 2 & 9 \\
\hline Total & 70 & 85 & 97 & 88 & 340 \\
\hline
\end{tabular}

Fonte: Arquivos da CPT com levantamento realizado no GPTEC. Em negrito, os meses com maior incidência de depoimentos. Em iłálico, os com menor incidência.

com quatro e dezembro, dois. $\mathrm{O}$ quadriênio com menor número de depoimentos, de 2004 a 2007, vai de outubro a dezembro, com 59. Isto coincide com os meses de chuva, salvo julho, que é período de seca.
Qual é a razão disso? A informação tem alguma relevância? O recorte mais revelador é o das chuvas e da seca ou o do semestre? Se tomarmos em conta 0 período das chuvas, conhecido regional- 
mente como "inverno", ou das secas, conhecido como "verão", tem algum significado quanto ao aliciamento ou à fuga? Aparentemente, na região paraense do sudeste do Pará, local onde a maioria dos trabalhadores esteve, o período mais propício ao aliciamento e à fuga é o período da seca que inicia em maio e se estende até outubro. As estradas são mais transitáveis, o trabalho tem um rendimento maior, enquanto no período compreendido entre novembro e abril as chuvas são torrenciais, o transporte se torna cada vez mais precário, dadas as condições das estradas, e o trabalho segue em ritmo mais lento. Ora, o trabalhador ao ser aliciado no início da seca teria tem- po de compreender as ciladas da dívida, perceber $\circ$ tratamento degradante que estaria sendo submetido e empreenderia a fuga antes das novas chuvas. Isso, contudo, não foi o que apareceu nos depoimentos relativos a 2007 .

Nos 88 depoimentos de 2007, 73 revelaram informações sobre o mês de aliciamentos realizados neste mesmo ano ou em anos anteriores. Constatou-se que em todos os meses houve aliciamento e predominou aliciamentos no período das chuvas, 40 (54,79\%) (conf. Quadro 4). Qual é a razão? Como os fazendeiros estavam em situação irregular, preferiam manter os trabalhadores neste período, mesmo

Quadro 4. Meses de aliciamento, conforme depoimentos recolhidos em 2007.

\begin{tabular}{|l|c|c|c|c|c|c|c|c|c|c|c|c|}
\hline Mês do aliciamento & jan & fev & mar & ab & mai & jun & jul & ago & set & out & nov & dez \\
\hline Número de depoimentos & 13 & 8 & 5 & 8 & 5 & 9 & 11 & 3 & 4 & 1 & 2 & 4 \\
\hline
\end{tabular}

Fonte: Arquivos da CPT com levantamento realizado no GPTEC. Os meses se referem aos depoentes que haviam sido aliciados entre 2005 e 2007

Quadro 5. Número e porcentagem de fiscalizações empreendidas pelo Grupo Móvel no Pará, de 1996 a 2006.

\begin{tabular}{|c|c|c|c|c|}
\hline Ano & Período & & \\
\hline & Outubro a & março & Abril a & setembro \\
\hline 1996 & $\begin{array}{c}\mathbf{N}^{\circ} \\
\text { fiscalizações }\end{array}$ & $\%$ & $\begin{array}{c}\mathbf{N}^{\circ} \\
\text { fiscalizações }\end{array}$ & $\%$ \\
\hline 1997 & 4 & 3,3 & 5 & 1,9 \\
\hline 1998 & 0 & 0,0 & 5 & 1,9 \\
\hline 1999 & 1 & 0,8 & 11 & 4,3 \\
\hline 2000 & 1 & 8,8 & 15 & 5,8 \\
\hline 2001 & 10 & 8,1 & 6 & 2,3 \\
\hline 2002 & 8 & 6,5 & 8 & 3,1 \\
\hline 2003 & 10 & 8,1 & 40 & 15,6 \\
\hline 2004 & 38 & 30,9 & 87 & 33,9 \\
\hline 2005 & 17 & 13,8 & 30 & 11,7 \\
\hline 2006 & 23 & 19,5 & 25 & 9,7 \\
\hline Total & 10 & 8,1 & 25 & 9,7 \\
\hline
\end{tabular}


Quadro 6. Número e porcentagem de fiscalizações empreendidas pelo Grupo Móvel no Pará, entre 1996 e 2006

\begin{tabular}{|l|c|c|}
\hline \multicolumn{1}{|c|}{ Meses } & $\begin{array}{c}\text { Período } \\
\text { 1996- 2006 }\end{array}$ & \\
\hline & $\begin{array}{c}\mathbf{n}^{\circ} \\
\text { fiscalizações }\end{array}$ & $\%$ \\
\hline Outubro a março & 123 & 32,37 \\
\hline Abril a setembro & 254 & 67,63 \\
\hline Total & 380 & 100 \\
\hline
\end{tabular}

Fonte: Arquivos da CPT com levantamento realizado no GPTEC.

que a produtividade diminuísse pois, com as estradas mais precárias, havia menos fiscalizações? Ora, se é assim, no período anterior à existência do Grupo Móvel e à presença do Ministério Público do Trabalho com as penalizações cada vez mais graves, o aliciamento e as fugas se davam mais frequentemente no "verão"? Para tentar responder esta pergunta, o caminho era verificar o período no qual a fiscalização foi realizada. Como este objetivo, foi feito um levantamento sobre a data das fiscalizações realizadas pelo Grupo Móvel, entre 1996 e 2006, no Pará, a partir de 380 relatórios existentes no arquivo do GPTEC (Quadros 5 e 6$)^{46}$. $E$, de fato, é perceptível que nestes 11 anos, o único ano no qual a fiscalização predominou nos meses das chuvas foi 2000: 10 fiscalizações contra seis. Em 2001, o número de meses no período das chuvas coincidiu com o da seca: foram 8 as fiscalizações. Se levarmos em conta que outubro é o início das chuvas e que, em geral, as estradas estão ainda transitáveis, e não é tão difícil para o Grupo Móvel se locomover, temos três fazendas fiscalizadas em 2000 e duas no ano seguinte. De qualquer forma, nos demais anos, as fiscalizações se deram majoritariamente no período da seca, no "verão";

46 Agradecemos a Adriana Freitas, Vera L. Cavalieri, Rafael Palmeira e Luciana. D'Arrochella pelo levantamento destes dados. de tal forma que das 380 fiscalizações, $254(67,63 \%)$ se realizaram entre maio e setembro (Quadro 6).

\section{Como foi recolhida a denúncia}

Ao serem recebidas, as denúncias passaram por uma classificação na CPT. Podiam ser consideradas como trabalho escravo, possivelmente trabalho escravo ou super -exploração. Trabalho escravo, definiu a Comissão, "tem como elemento essencial e central a sujeição do trabalhador, que pode ser física e ou psicológica. A dívida crescente e impagável tem sido um dos meios mais utilizados para tornar o trabalhador cativo". Quanto a situações de superexploração, estas

acontecem na esfera salarial, dizem respeito às situações em que as horas de trabalho não pagas pelo empregador excedem a taxa normal de exploração do trabalho. Geralmente estes casos estão ligados a precárias condições de trabalho e moradia; o desrespeito trabalhista que tem como referência a legislação vigente e está ligado especialmente às condições de trabalho (CPT, 2009: 13).

Os agentes sociais, ao recolherem as denúncias ao longo dos anos, se preocuparam em registrar o nome do informante, a data da informação, o nome e o município da unidade de produção. Resumiam a história do trabalhador e registravam o município de seu nascimento, a moradia e o lugar do aliciamento, a viagem, a dívida, o trabalho, as coerções sofridas e a violação das leis penais e trabalhistas. Alguns depoimentos foram extensos; outros curtos; alguns, minuciosos; outros lacônicos e incompletos. Em geral, as denúncias colhidas em 2007 atendiam um minucioso "Formulário de Recepção Denúncia de Trabalho Escravo", que podia ocupar quatro pági- 
nas, separado em quatro itens, além do cabeçalho e das notas. Os itens eram assim distribuídos: 1. Dados do denunciante e meios de contato; 2. Descrição do contrato; 3. Local e descrição das atividades; 4. Caracterização da situação análoga à escravidão. A observação final destacava que, para ser efetuado o atendimento da denúncia, dependia do bom preenchimento do formulário; e as denúncias que não caracterizavam trabalho degradante, mas irregularidade trabalhista deveriam ser enviadas às Delegacias Regionais do Trabalho47. O CDVDH/Açailândia seguiu o modelo com adaptações.

O Centro de Direitos Humanos de Ananás ainda colheu, em 2007, os depoimentos na forma anterior: um título, o resumo do lado esquerdo da página que previa a inserção no local do nome da fazenda, do município, do proprietário, da especificação da atividade e do número de trabalhadores envolvidos. A seguir, o texto único da declaração, com a assinatura do depoente e da testemunha e a data. Em julho, um depoimento colhido pela CPT/ Tucumã, manteve o estilo anterior ${ }^{48}$.

Percebeu-se em alguns depoimentos, mesmo nos mais antigos, foi a descrição do caminho para se chegar à fazenda - a distância, a condição da estrada, a existência da ponte, de curvas, porteiras e placas de fazenda ou de publicidade, algum comércio na estrada, noções de direção: "entrar à esquerda", "direita", "seguir em frente", aspecto físico de construções no caminho ${ }^{49}$.

\section{Quem e como prestou o depoimento}

Os depoimentos foram em geral colhidos de trabalhadores, mas, dos 66 depoi-

\footnotetext{
47 Neste caso, a prática revela que é considerado trabalho escravo não apenas - que a organização define no seu Caderno de Conflitos (CPT, 2009, p. 13), mas aquilo que é caracterizado pelo Artigo 149 do Código Penal Brasileiro.

48 Documento 43 de 10.07.07, relativo à frazenda do Cléber, Ourilândia do Norte.

49 Documento 28 de. 27.04 .07 , relativo à fazenda Pau Terra, Rondon do Pará Dourados em Vitória do Xingu- 2004.
}

mentos de 2004, houve três provenientes de gatos que tiveram desavenças com proprietários e/ou peões; de 85 depoimentos, de 2005, dois também vieram de gatos $^{50}$. Estes, em um e outro caso, eram intermediários pequenos, tão pobres quanto os demais trabalhadores. Em oito declarações $(9,3 \%)$ de 2005, com histórias de unidades de produção carvoeira e agropecuária, houve implícita ou explicitamente a informação de presença de peões do trecho entre os depoentes. Em um só caso, o trabalhador se apresentou desta forma, contudo os demais derram sinais de o serem quando revelavam não ter "moradia", "endereço fixo", ou passar de hotel em hotel. ${ }^{51}$

As denúncias se deram muitas vezes de forma individual. A maior parte $(62,9 \%)$ dos informantes de 2005, por exemplo, as formularam sós; mesmo se a situação fosse adversa. Em um caso, por exemplo, o trabalhador foi levado por amigos porque não conseguia andar, fraco por causa da fome. Tanto estes, quanto àqueles que foram acompanhados por uma ou mais pessoas saíram ou fugiram de unidades de produção ligadas a atividades agropecuárias ou de carvoaria, salvo um dos depoimentos, no qual um homem não esteve submetido ao trabalho, mas denunciou o desaparecimento de filho ${ }^{52}$.

Houve também denúncias realizadas em grupo de duas ou mais pessoas. Há caso

\footnotetext{
50 Documento de 29.08.05, relativo à fazenda São Judas, São Félix do Xingu. 51 Tem 55 anos, mas não tem moradia (Documento de 22.04.05, relativo à fazenda de Beto Basílio, N.I.); (do Toninho da Ladeira, São Félix do Xingu); não tem endereço fixo (17.05.05. Carvoaria de Osmar Gomes de Carvalho, Dom Elizeu; Documento de 16.10 .05 relativo à fazenda de Suiço, Anapu); os três, apesar da idade, moram em casa de outros (Documento de 13.01.05. Primavera, Rio Maria); não tem residência fixa (Documento de 16.08 .05 relativo à fazenda Mundial, Água Azul do Norte); contratado em hotel (18.07.05. Sete Barracos, Floresta); os três, depois de trabalharem nas fazendas vizinhas, procuram trabalho com $\circ$ gato... Um sem endereço fixo (29.08.05. São Cristóvão, São Félix do Xingu). do "trecho": 23 anos, família mora no Maranhão, dorme na rua em Marabá (Documento de 22.03.06. do dr. Djalma, Marabá); sem moradia fixa (27.03.06 relativo à fazenda Alvorada, São Félix do Xingu. Documento de 03.04.06 relativo à fazenda do Nilton, Goianésia); solteiro e morava na carvoaria onde tinha acabado de chegar (Documento de 08.05.10 relatgivo à. Carvoaria do Douglas, Goianésia); sem residência fixa (14.06.06 relativo à Serraria do Jaime, Castelo dos Sonhos; 22.09.06 relativo à fazenda do Polako, Uruará. 120 trabalhadores; Documento de 13.10 .06 relativo à fazenda do Juca, Abel Figueredo); solteiro e sem endereço fixo (Documento de 15.12.06 relativo à fazenda do Aélcio, ltupiranga).

52 Documento de 05.02 .05 relativo à fazenda do Neto, Pacajá. Documento de 22.05.06 relativo à fazenda Rio Branco, Ourilândia.
} 
no qual vão pai e filho e o primeiro revela que outro filho foi morto; ou quem depõe é uma mulher, um menor, ou dois menores em um grupo de mais de nove homens ou cinco menores de um grupo de nove trabalhadores depuseram. Podiam depor dois trabalhadores, um do trecho, outro não; um mais velho, outro jovem; um jovem, outro menor; um sem documento - por que deixou na fazenda, porque perdeu - outro com documento; em um caso, um tinha perdido o documento, outro tinha o documento penhorado em um comércio; um da região, outro não; ou ambos da mesma cidade; ou de três estados distintos. A pessoa falava por si, tinha fugido ou saído sem que os demais soubessem; ou tinha saído representando os demais e falar em nome do grupo e para isso até "encabeçar um abaixo assinado". O trabalhador era muito articulado, conhecia o pessoal do STR, utilizava telefone, procurava advogado na cidade; tinham ou não diferença de idade e de estado civil ${ }^{53}$.

Foi, em nome próprio ou do grupo, denunciar o que representava perigo e produzia medo. Era uma ocasião de formular a reclamação contra a unidade de produção da qual acabava de escapar, mas podia na ocasião revelar problemas vividos em outras fazendas ${ }^{54}$.

53 .Documento de 11.10 .05 relativo à fazenda Panorama, n. i. Em outro caso, um trabalhador ao denunciar uma fazenda, denunciou também outra, onde um vaqueiro teria sido assassinado e trabalhadores viviam sérios problemas. Ele mesmo havia trabalhado ali por mais de 7 anos e havia sido expulso (documento de 10.07.06 relativo à fazenda Santa Maria, Marabá). Documento de 31.01.06 relativo à fazenda Quatro Reis, S. Félix do Xingu; Documento de 25.05 .06 , relativo à fazenda Maria Junqueira, Uruará; Documento de 07.08 .06 relativo à fazenda do Chiquinho, Novo Repartimento; Documento 33.de 03.05.10, relativo à fazenda do Maquinon, Marabá; Documento de 11.04.06, relativo à fazenda do Wilson. Goianésia; Documento de Abril 06, relativo à fazenda Rio Vermelho, Sapucaia Documento de 21.06.06 relativo à fazenda Bela Moça, São Félix do Xingu; Documento de 03.05 .10 , relativo à fazenda. do Maquinon, Marabá; Documento 31. Sapucaia; Documento de 25.04.06, relativo à fazenda Iraque, Eldorado do Carajás; Documento de 21.06.06, relativo à fazenda Bela Moça, São Félix do Xingu; Documento de Abril 06, relativo à fazenda Rio Vermelho, Sapucaia; Documento de 03.04.06 relativo à fazenda do Nilton, Goianésia; Documento de 03.05 .10 relativo à fazenda do Grapuá, Uruará; Documento de 24.04 .06 relativo à fazenda Entro das Águas, Pacajá; Documento de 21.06 .06 relativo à fazenda Bela Moça, São Félix do Xingu

54 Documento de 05.09 .05 relativo à fazenda Sem Nome, Rondon do Pará Documento de 22.04.05 relativo à fazenda de Beto Basílio, N. I; houve ainda um depoente que havia feito anteriormente outra denúncia contra outra fazenda, o Grupo Móvel tinha autuado a fazenda. Ele não foi beneficiado por estar foro por ocasião da fiscalização (documento de 11.09 .06 relativo à fazenda Água Azul, ltupiranga).
Em geral, os depoimentos foram feitos por homens, casados ou solteiros ${ }^{55}$, com mais de 18 anos. Contudo, em dois depoimentos $(2,32 \%)$ houve menores. No primeiro caso, tratava-se de um adolescente de 17 anos que prestava as informações com outros jovens de 23 e 25 anos. Estes haviam sido aliciados para o trabalho de "juquira" ${ }^{56}$. No segundo caso, seis pessoas depuseram, entre elas, dois menores, provavelmente irmãos ${ }^{57}$. Em outros anos, como em 2004, houve também uma diversidade de formas nos depoimentos. Às vezes era o casal que prestava 0 depoimento ${ }^{58}$, ou em grupo de duas ou mais pessoas, composta por amigos ou conhecidos $^{59}$.

Os depoimentos foram recolhidos na primeira pessoa do singular ou do plural; ou na terceira pessoa do singular ou do plural e o trabalhador era reconhecido como "declarante" ou "depoente", dependendo da pessoa ou lugar onde é recolhido. Nos depoimentos realizados na primeira pessoa, os trabalhadores se pronunciavam diretamente, como se houvesse uma transcrição literal. Nos depoimentos recolhidos na terceira pessoa havia mais formalidade. O agente, que recolhia, deixava visível a marca da sua instituição e esta forma lembrava as declarações realizadas em estabelecimentos públicos, como delegacia policial e poder judiciário. Era possível constatar, por exemplo, que pouco mais de 17\%, das declarações foram tomadas na primeira pessoa do singular ou do plural. Destes, a grande maioria, dois terços, foi recolhida pela CPT de Xinguara. Os demais depoimentos se dividiam igualmente

55 Documento de 16.08 .05 relativo à fazenda Mundial, Água Azul do Norte 56 "Juquira" significa a limpeza de mato denso que cresce em área anteriormente derrubada e formada em pasto. 11.03.05 relativo à fazenda Jesus Batista, Água Azul do Norte.

57 17.05.05 relativo à Carvoaria de Osmar Gomes de Carvalho, Dom Elizeu. 58 Documento de 05.04 relativo à fazenda Mococa, Bom Jesus do Tocantins. 59 Documento de 28.04.04 relativo à fazenda São José. Roço de pasto; documento de 21.05.04 relativo à fazenda Bela Vista, S. Félix do Xingu, $1^{\circ}$ e $2^{\circ}$ documento de 12.02.04 relativo à Carvoaria do Dimas. Dom Elizeu. 
entre os escritórios da CPT de Marabá, Tucumã e São Félix do Xingu. Um último depoimento foi recolhido em Açailândia, provavelmente pelo Balcão do Direito e pelo Centro de Defesa da Vida e dos Direitos Humanos. Mais de $80 \%$ dos depoimentos foram recolhidos na terceira pessoa do singular ou plural, sendo a grande maioria destes, - mais de 66\%recolhidos pela CPT de Marabá, alguns pela CPT de Araguaína, e os demais, menos numerosos, foram os recolhidos pelos STR de Redenção e Rondon do Pará, pelas delegacias Regionais do Trabalho de Marabá e Araguaína pelo Balcão do Direito e pelo Centro de Defesa da Vida e dos Direitos Humanos de Açailândia. A CPT de Xinguara que até então tomava os depoimentos na primeira pessoa do singular ou plural, em 2007 passou a tomar os depoimentos na terceira pessoa do singular e/ou do plural.

Alguns trabalhadores, em 2006, se apresentavam sem documentos porque não tinham, perderam, houve extravio, foram roubados, esqueceram em casa ou outro lugar. $E$, entre os trabalhadores do mesmo ano, houve aqueles que revelam "não ter leitura"; não serem alfabetizados; terem a primeira série do ensino básico, ou só terem a primeira série e só sabem "assinar"; a segunda série; a terceira, a quarta série incompleta; a quarta; a quinta; a sétima e a oitava série. Há um depoente que revela ter o estudo médio completo e outro que até o terceiro ano de administração de empresas.

\section{O telefone como instrumento da denúncia}

Em reunião realizada em Goiânia e promovida pela CPT para discutir o trabalho escravo, com a presença auditores fiscais do trabalho, procuradores da república e do trabalho, professores universitários, militantes dos direitos humanos, um dos membros da pastoral apresentou materiais pedagógicos informativos para serem distribuído a trabalhadores rurais. Um dos materiais tinha o formato de uma "sanfoninha", elaborado em papel resistente que, com diversas dobras, cabia no bolso da camisa ou na carteira de documentos. Constava naquele papel uma pequena história em quadrinhos, um texto informativo e números de telefone para serem $^{60}$ acessados em caso de necessidade. Na ocasião, um dos conferencistas, professor em São Paulo, demonstrou estranhamento. Para ele, trabalhador rural não usava telefone.

Alguns, porém, mesmo se raros, usavam telefone e começou a se difundir seu uso em áreas rurais e o aparelho, como previa a organização, se tornou um instrumento novo para que peões formulassem denúncias, mantivessem contatos com a família e fossem contatados posteriormente. Em três casos, em 2004, a comunicação foi realizada por telefone e em um caso o depoente deixou um número para contato ${ }^{61}$. Nos anos seguintes, trabalhadores voltaram a utilizar o mesmo instrumento.

Em 2005, por exemplo, a CPT de Xinguara recebeu um telefonema de lavradores que haviam escapado de uma fazenda. $O$ grupo marcou uma visita ao escritório quando, pessoalmente, relatou o ocorrido ${ }^{62}$. Em maio e outubro do mesmo ano, o escritório da CPT de Araguaína foi contatado por quatro telefonemas realizados em aparelhos públicos de cidades diferentes, do Pará e do Tocantins ${ }^{63}$.

\footnotetext{
60 Desta reunião foi publicado um livro com artigos provenientes de diversos atores envolvidos com o tema da escravidão contemporânea (CPT: 1999)

61 a. CPT /Araguaína: 25.05.04. Barra do Dia, Marabá; b. Balcão do Direito e Centro de Defesa da Vida/Açailândia: depoimento 63 de 03.11 .04 , relativo à fazenda Carvoaria da Viena AS, Ulionópolis; c. CPT/Araguaína. (Documento 6 de 27.01.04, relativo à fazenda Laços de Ouro. São Geraldo; d. CPT/Araguaína: documento 69 de 27.01.04 relativo à fazenda Laços de Ouro. São Geraldo (tel. de contato).

62 Documento de 07.01.05, relativo à fazenda Faz. Zeca Batista, Água Azul do Norte.

63 Documento de 11.05.2005, relativo à fazenda Água Azul, São Geraldo do Araguaia, documento de 25.10.05 relativo à fazenda Serra Grande, Brejo Grade documento de 25.10 .05 relativo à fazenda Sebastião Pereira, de Ananás e documento de 08.11 .05 relativo à fazenda Cachoeirinha, São Geraldo do Araguaia.
} 
Há o caso do trabalhador que há mais de um ano estava com a esposa e os filhos em uma fazenda em São Félix do Xingu e se comunicou por telefone com a mãe. Sem dinheiro não podia sair, o local era de difícil acesso e, para sair, só de avião. Enquanto pedia socorro, o gerente da fazenda cortou a ligação. A mãe relatou o fato ao Núcleo de Direitos Humanos de Ananás/Tocantins ${ }^{64}$.

A CPT/Marabá foi acionada duas vezes, em 2006, por trabalhadores. Na primei$\mathrm{ra}$, o depoente, depois de ter ido pessoalmente ao escritório, telefonou para deixar o número de celular de um vereador que poderia ser seu contato futuro; outro trabalhador ligou de um orelhão e deixou o número do celular da cunhada. Alguns meses depois, em novembro, um trabalhador ligou do Pará para a CPT/Araguaína, prestou a sua denúncia e deixou o número do celular da vizinha. Quatro outros trabalhadores, em novas denúncias, no transcorrer dos seus depoimentos, deixaram algum número de telefone que poderia ser próprio, ou o número de um aparelho público, o chamado "orelhão", e o número de um celular de um amigo, do irmão, de uma loja, o número de um "orelhão" no Maranhão e o número de uma pensão no Paráb5.

A utilização do telefone por parte dos trabalhadores, em 2007, foi mais frequente: $25 \%$ dos depoentes fizeram uso dele, enquanto no ano anterior os números de telefone ou informações sobre telefones alcançaram apenas $7,2 \%$ dos depoimentos. E as informações relativas a 2007 se dão ou porque os depoentes tinham $\circ$ aparelho; ou porque

64 Documento de 18.02.05, relativo à fazenda Iriri, São Félix do Xingu.

65 Documento 24 de 28.03.06, relativo à fazenda Ouro Preto e Esmeralda, Palestina ; documento 30 de 24.04.06, relativo à fazenda Entro das Águas, Pacajá ; documento 89 de 23.1 1.06, relativo à Carvoaria do Gaúcho, Eldorado dos Carajás; documento 36 de 04.05.10, relativo à fazenda Vale do Itinga, Dom Eliseu documento 40 de 10.05.10, relativo à fazenda Valadares, Ourilândia; documento 70 de 11.09.06, relativo à fazenda Água Azul, Itupiranga; documento 78 de 16.10.06, relativo à fazenda Jesus de Nazaré, Abel de Figueredo. tiveram acesso ao telefone da unidade de produção, ao telefone público ou porque tinham amigos ou parentes que cediam seus aparelhos para receberem recados.

Tudo isso revelava a maior difusão do uso do telefone mesmo nas camadas mais empobrecidas de áreas rurais. Além de três depoimentos de escritórios diferentes da CPT serem extraídos de telefonemas recebidos, alguns dos denunciantes deixaram nos escritórios da CPT um número de telefone para comunicações posteriores. Alguns dos depoentes Juniormar e Maria; Salvador Raimundo tinham telefone; Benedito e Raimundo, um número que talvez fosse do segundo;i Edvan, dois números de celulares e o casal, Leomário e Maria Divina, o número de telefone público. Contudo, os demais que o fizeram, deixaram números de parentes - da filha); do irmão ou irmãs; da esposa e da cunhada. Um dos exemplos foi o do peão do trecho, Manuel. Mesmo estando fora de casa havia tempo, não ter moradia certa, ter uma referência, o telefone fixo da mãe, que morava no Maranhão $0^{66}$.

Houve ainda aqueles que, em 2007, deixaram números de aparelhos de amigos. Antônio deixou o de dona Maria e Jeová, o do companheiro Pequeno. Alessandro deixou três números de celulares de amigas e uma era cozinheira da fazenda; Zé Maria, o do vizinho em Tucuruí; Aldey, o da vizinha; Raulino, o do Zé Arlindo; Zé Carlos, o de Aline; Zé Maria, do vizinho

66 Os escritórios da CPT/de Marabá (1b). 26.01.07 relativo à fazenda SerraGrande, Palestina); Tucuruí (Documento de 07.02.07, relativo à fazenda. Verena, Novo Repartimento/Marabá); e Araguaína (Documento 33. 31.05.07, relativo à fazenda São José, Brejo Grande); documento 22 de 10.04.07, relativo à fazenda Santa Marta, Ourilândia ; Documento 26 de. 23.04.07, relativo à fazenda Aratau, Pacaiá ; documento 65 de 29.10.07, relativo à fazenda do Arquimede Rocha, Tucuruí; documento 09.02 (?3).06, relativo à fazenda Rio Grande, ltupiranga ; documento 27 de 26.04.07, relativo à fazenda Novo Brasil, Goianésia ; documento 20 de 09.04.07, relativo à fazenda Tocantins. Itupiranga ; documento 24 de 16.04.07] relativo à fazenda São Francisco, Palestina; Documento 11 de 26.02.06, relativo à fazenda do Amador, Itupiranga; Documento 62 de 01.10.07, relativo à fazenda Paracanã, Tucuruí; 67. 05.1 1.07. do Nélio Baiano, São Geraldo do Araguaia; Documento 54 de 27.08.07, relativo à fazenda Talismã, Itupiranga documento 68 de 07.11.07, relativo à fazenda Carvoaria e fazenda Águas Claras, Ipixuna 
Edson; Zé Aldey, da Cida e Raulino, o celular de Zé Arlindo.67

Em um depoimento não constava número de telefone deixado pelo trabalhador, contudo, no final, havia a observação de que ele seria avisado por telefone sobre a fiscalização, o que revelava a possibilidade de estabelecer tais contatos. Provavelmente, o trabalhador levou consigo o número de telefone do escritório ${ }^{68}$.

Há outras informações sobre o uso do telefone. Aqueles que coletaram os depoimentos, orientados pelo formulário, perguntaram a respeito do endereço do empregador e de seu número de telefone. Salvo raras exceções ${ }^{69}$, boa parte não tinha tais informações. Em um dos casos estudados, três trabalhadores revelaram que tinham o número e já o haviam acionado. Eles foram contratados em junho de 2007 no Tocantins e, quatro meses depois, ainda não haviam recebido pelo serviço prestado, não tinham rede, dormiam no chão, e faltava comida, por isso, explicaram: "foram a pé até uma vilinha perto da fazenda e pegaram carona até a cidade de São Geraldo do Araguaia. (...) ligaram para o Sr. N., mas que quando o mesmo percebia que era eles, logo desligava o telefone"70.

Além de telefone, algumas fazendas utilizavam o rádio amador como forma de manter contato e controle. Ou, o proprietário utilizava o telefone de uma forma que preocupava os depoentes, como foi o caso citado anteriormente do traba-

67 Documento 14.02.07, relativo à fazenda relativo à fazenda Sucupira, Rio Maria; Documento de 30.03.07, relativo à fazenda Fábrica de Palmitos, Pacajá ; Documento 42 de. 09.07.07, relativo à fazenda Santo Antônio, Tailândia; Documento 80 de 27.02.07, relativo à fazenda Bandeirante, Baião; Documento 84 de 03.08.07, relativo à fazenda Tarumã, Santa Maria das Barreiras; Documento 44 de 13.07.07, relativo à fazenda Monte Sião, Rondon do Pará; Documento de 22.02.07, relativo à fazenda Atleticana, Rondon do Pará; Documento 80 de 27.02.07, relativo à fazenda Bandeirante, Baião; Documento 84 de 03.08.07, relativo à fazenda Tarumã, Santa Maria das Barreiras; Documento 44 de 13.07.07, relativo à fazenda Monte Sião, Rondon do Pará

68 Documento de 10.04 .07 , relativo à Carvoaria na faz. do Miguel, Marabá.

69 Documento de 23.02.07, relativo à fazenda Indiaçu, Palestina; Documento 67 de 05.11.07. do Nélio Baiano, São Geraldo do Araguaia..

70 Documento 67 de 05.11.07, relativo à fazenda do Nélio Baiano, São Geraldo do Araguaia.
Ihador que ao procurar a promotora da comarca esta conversou por telefone com o fazendeiro.

\section{CONCLUSÃO}

As denúncias foram elaboradas especialmente por adultos jovens, pessoas do sexo masculino, mas houve adolescentes, idosos e mulheres. Os denunciantes depuseram de muitas formas. Alguns sós; outros acompanhados; uns falaram sobre si; outros em seu próprio nome e do grupo; todos reclamaram de uma ou mais pessoa; de gente que assumia função igual ou diferente na escala do mando e na relação do trabalho. Quanto ao período do ano escolhido ou propício para - aliciamento e a denúncia, a resposta não está suficientemente respondida, mas os dados apontam para uma hipótese. O período das chuvas seria o melhor para se evitar a fiscalização do Estado e, por isso, uma das razões dos aliciamentos realizarem-se justamente nesta época.

Os trabalhadores formularam, no período estudado, uma média anual superior a 80 depoimentos; mais de sete depoimentos por mês e procuraram aqueles que os ouviram em cidades diferentes e em organizações distintas, especialmente os escritórios da CPT.

Entre muitas perguntas ainda a serem formuladas, caberia, por exemplo: por que tantas denúncias? E qual a razão da CPT ser procurada com tal frequencia?

Quanto à primeira pergunta: de fato as denúncias sobre trabalho escravo são numerosas, mesmo se o crime não é numericamente superior ao que era nos anos anteriores à constituição do Grupo Móvel de fiscalização do MTE. Se isso for verdade, como explicar o aumento das denúncias? Antes, o número de denúncias era menor porque $\circ$ reconhecimento do problema 
como crime nem sempre existia e não havia muita expectativa quanto á ação do Estado. $O$ aumento das operações de fiscalização e o seu sucesso podem explicar - aumento das denúncias. Uma vez que uma denúncia era acolhida, havia uma probabilidade da ação do estado e o resgate dos trabalhadores. A Com uma novidade. Além do pagamento do salário devido, das férias, do décimo terceiro, as pessoas eram incluídas no salário desemprego e, em alguns casos, através de Termo de Ajuste de Conduta, recebiam uma indenização.por dano moral individual. Se a lógica do empregador era "quem deve, paga", e era compartilhada por muitos trabalhadores, presenciar os auditores fiscais e procuradores do trabalhado repreender duramente empregadores e seus prepostos, apontar em minúcias cada infração e crime, se tornou uma aula de cidadania e de formação de nova consciência de direito. As campanhas empreendidas pela CPT e pela Repórter Brasil de informação sobre o crime; o aumento de veiculação de notícias por redes de televisão e jornais, tudo isso favoreceu ao desvendamento de um problema que circulava pelas unidades de produção sem ser reconhecido como um problema.

Quanto à segunda pergunta, desde sua criação em meados dos anos 1975, a CPT se dedicou ao tema, criou escritórios em locais de passagens de trabalhadores ou locais estratégicos de aliciamento, uma rede de informação, uma metodologia, dialogou com a sociedade, pressionou autoridades, e acabou por se tornar uma referência para os trabalhadores e para o próprio governo. Procurada, tinha experiência em ligar com o assunto e acolhia os trabalhadores qualquer hora do dia ou da noite, ouvia-os, se preocupava com a saúde da pessoa, com sua alimentação, como o alojamento temporário e desencadeava pressões sobre as autoridades. Ao mesmo tempo, algumas autoridades, sem estrutura ou experiência, encaminhavam os depoentes à CPT.

\section{REFERÊNCIAS BIBLIOGRÁFICAS}

ALMEIDA, Alfredo W. B.1988. O trabalho como instrumento de escravidão. Humanidades. (V):17:59-67.

BALES, Kevin. 2001. Gente descartável. Lisboa: Editorial Caminho.338 p.

BOUCLET, Benjamin. 2005. Entre tecnologia e escravidão: a aventura da Volkswagen na Amazônia. Rio de Janeiro. O social em questão. Pontifícia Universidade Católica do Rio de Janeiro.(20): 33-50.

COSTA, Patrícia T. M. 2010. Combatendo o trabatho escravo contemporâneo: o exemplo do Brasil. Brasília: OIT. Satellite Gráfica e Editora Ltda, 191 p.

CPT. 2010. Conflitos no campo Brasil 2009. CANUTO, A., LUZ, Cássia Regina da S., WICHINIESKI, Isolete (Orgs.). São Paulo, CPT/SP: Expressão Popular, 200 p.

1999.Trabalho escravo contemporâneo. Goiânia: CPT. 87 p.

CASTILLO, Ela W. Volkmer de. 2008. As ações do Ministério Público Federal e os limites do Poder Judiciário na erradicação do trabalho escravo. In: DE CERQUEIRA, G. C. et al (Orgs.). 2008.TrabaIho escravo contemporâneo no Brasil. Contribuições críticas para sua análise e denúncia. Rio de Janeiro: Editora UFRJ.p. 169-182.

CAVALCANTE et al. (Orgs.). 2008. Trabalho escravo contemporâneo no Brasil. Contribuições críticas para sua análise e denúncia. Rio de Janeiro: Editora UFRJ. $350 \mathrm{p}$.

ESTERCI, Neide. 1994. Escravos da desigualdade: estudo sobre o uso repressivo da força de trabalho hoje. Rio de Janeiro: Cedi. 135 p.

FIGUEIRA, Ricardo Rezende. 2009. A escravidão contemporânea no Brasil: de 1985 a 2009. In: SIDOW, e MENDONÇA, M. L. (Org.). Direitos humanos no Brasil 2009. Relatório da Rede Social de Justiça e Direitos Humanos. São Paulo: Rede Social de Justiça e Direitos Humanos, pp. 83-94. 
2004. Pisando fora da própria sombra. A escravidão por dívida no Brasil contemporâneo. Rio de Janeiro: Civilização Brasileira. 445 p.

FIGUEIRA, Rezende. R. e PRADO, Adonia. A. 2009. O Trabalho Escravo por dívida: discussões e persistência. In:Ciclo Cidadania em Debate / Maria Helena Versiani e Núbia Melhem Santos. (Orgs.). Rio de Janeiro: Jauá: Museu da República, p. 74-87.

HENRIQUES, Isabel C. 2002. A revisão da escravatura e do tráfico negreiro em Moçambique (1733-1904) na obra de José Capela. Africana Studia. Revista internacional de Estudos Africanos. Centro de estudos Africanos, Universidade do Porto. Porto, (5): 213-226.

LE BRETON, B. 2002.Vidas roubadas. A escravidão moderna na Amazônia brasileira. São Paulo: Loyola. 278 p.

MARTINS, José. de S. 1995.A reprodução do capital na frente pioneira e o renascimento da escravidão no Brasil. In: Tempo Social, Revista de Sociologia. USP. (6): 1-2, 1-25.

MOORE JR., Barrington. 1987.Injustiça: as bases sociais da obediência e da revolta. São Paulo: Brasiliense. $711 \mathrm{p}$.
MOURA, Flávia. de A. 2009. Escravos da precisão. Economia familiar e estratégias de sobrevivência de trabalhadores rurais em Codó (MA). São Luiz: UFMA. 128 p.

ORGANIZAÇÃO INTERNACIONAL DO TRABALHO. Perfil dos principais atores envolvidos no trabalho escravo rural. Brasília, OIT.176 p.

PRADO, Adonia A. 2010. Trabalho escravo contemporâneo: uma questão para o Estado e para a sociedade civil. Versus. Revista de Ciências Sociais Aplicadas do CCJE/UFRJ. Rio de Janeiro, Universidade Federal do Rio de Janeiro, (II): 4: $121-123$.

SANTOS, Maciel M. 2002. A rentabilidade do cacau de S. Tomé e Príncipe - hipóteses de explicação. Africana Studia. Revista internacional de Estudos Africanos. Centro de estudos Africanos, Universidade do Porto. Porto. (5): 181-212.

SUTTON, A. 1994.Trabalho escravo: um elo na cadeia da modernidade. São Paulo: Loyola. 176 p.

VV.AA. 1999.Trabalho escravo no Brasil Contemporâneo. São Paulo: Loyola/Comissão pastoral da Terra, 1999. 238 p.

ZANIN, Valter. 2007. I forzati del mare. Le Varianti, Roma: Carocci. 358 p. 